\title{
STEREOCHEMICAL ASPECTS IN THE CHEMISTRY OF HETEROCYCLIC COMPOUNDS
}

With the adoption of the FDA (Food and Drug Administration) declaration at the beginning of the 1980s it clearly became expedient to develop the new area of pharmacology and pharmacy associated with the creation of enantiomerically pure $(S)$ - and $(R)$-stereoisomers of drugs having the optimal balance of therapeutic effectiveness and safety.

At the present time, approximately $15 \%$ of all synthesized pharmacological preparations having a chiral center are represented by the pure enantiomers. The registration of racemic pharmaceutical preparations practically ceased from 2001. This trend has been reflected in the scientific literature of recent years in the term "chiral switch", which means to "turn toward chiral forms". There is an increasing interest at both the scientific and legislative circles towards the production of chiral drugs in the form of their active enantiomers .

Due to the fact that more than $60 \%$ of drugs from synthetic and natural

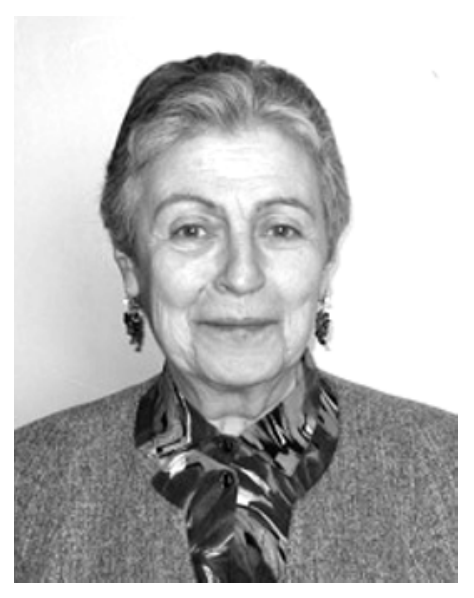
sources are represented by heterocyclic structures, the problem of stereoselective synthesis and investigation of the chiral optical properties of optically active heterocyclic compounds is an extremely important and pressing one.

This has prompted us to dedicate a special issue of the journal, in which reviews and research articles by leading scientific teams in this field are presented, to the problems of stereochemistry in heterocyclic compounds. Among the techniques featured in these papers, there are asymmetric synthesis, the use of chiral precursors, the introduction of auxiliary chiral groups, kinetic separation and related procedures, widely applied for the preparation of chiral heterocyclic compounds.

We hope that these publications will be of interest to the wider scientific community and will prove useful in further research.

Professor, Doctor of Chemical Sciences M. A. Yurovskaya, M. V. Lomonosov Moscow State University

Translated from Khimiya Geterotsiklicheskikh Soedinenii, No. 5, pp. 735, May, 2012 